\title{
Gravity anomalies and the geologic block structures in and around the aftershock area of the 2007 Noto Hanto Earthquake
}

\author{
Ryo Honda ${ }^{1}$, Yoshihiro Hiramatsu ${ }^{2}$, Yoshiteru Kono ${ }^{3}$, and Hideki Katagawa ${ }^{4}$ \\ ${ }^{1}$ Institute of Seismology and Volcanology, Hokkaido University, N10W8 Kita-ku, Sapporo, Japan \\ ${ }^{2}$ Graduate School of Natural Science and Technology, Kanazawa University, Kakuma, Kanazawa, Japan \\ ${ }^{3}$ Emeritus Professor of Kanazawa University, Kanazawa University, Kakuma, Kanazawa, Japan \\ ${ }^{4}$ Department of Civil Engineering, Hokuriku Electric Power Co., Ltd., 15-1 Ushijima-Cho, Toyama, Japan
}

(Received June 29, 2007; Revised September 17, 2007; Accepted October 4, 2007; Online published February 19, 2008)

\begin{abstract}
The 2007 Noto Hanto Earthquake occurred on 25 March. We have constructed a detailed gravity anomaly map over the Noto peninsula. Four block boundaries which are identified by morphological/geological studies are also recognized on the gravity anomaly map. Various other observations indicate that the mainshock ruptured only one of the blocks, the Kuwatsuka block, although aftershocks are distributed over two blocks, the Kuwatsuka and the Saruyama blocks. The Bouguer anomalies over the Kuwatsuka block are relatively high compared to those of the Saruyama block, i.e. the basement depth of the Kuwatsuka block is shallower than that of the Saruyama block. This difference in the basement depth is consistent with the deformation pattern observed by SAR interferometry. At the block boundary, an offset is recognized in the aftershock distribution. Based on the relationships among the gravity anomalies, the geologic structures, the aftershock distribution and the source fault, we propose that the rupture size of the earthquake was constrained by the block structure in this region.
\end{abstract}

Key words: Gravity anomaly, the 2007 Noto Hanto Earthquake, geologic block structure.

\section{Introduction}

The 2007 Noto Hanto (Noto Peninsula) Earthquake ( $M_{\text {JMA }}$ 6.9) occurred on 9:41, 25 March 2007. The reported focal mechanism was thrust with a right lateral slip component (Hoshiba, 2007). Seismic intensities over 6 (JMA scale) were observed around the source region, and several hundred houses were damaged. During the earthquake, one person was killed. The Noto peninsula is not a very seismically active region. This is the first $M 6$ class earthquake since 1993, which occurred off the north coast of Suzu city ( $\left.M_{\mathrm{JMA}} 6.6\right)$.

Katagawa et al. (2005) reported the acoustic stratigraphy in the Japan Sea off the west coast of the Noto peninsula obtained by single-channel seismic exploration. From the aftershock distribution, ERI (2007) proposed that the fault plane of this earthquake seems to be on a downward extension of the faults F14 and F15 reported in Katagawa et al. (2005).

We have compiled all of the gravity data available over the Noto peninsula (Kono et al., in preparation). Here, we discuss the relationships among the gravity anomalies, geologic structures, aftershock distribution and the source fault.

\section{Gravity Data}

On the land area, many institutes have obtained gravity data in and around the aftershock area. We have

Copyright (c) The Society of Geomagnetism and Earth, Planetary and Space Sciences (SGEPSS); The Seismological Society of Japan; The Volcanological Society of Japan; The Geodetic Society of Japan; The Japanese Society for Planetary Sciences; TERRAPUB compiled gravity data obtained by Kanazawa University (Kono and Furuse, 1989), Hokuriku Electric Co. Ltd. (unreleased), Geographical Survey Institute of Japan (GSI, 2002), Geological Survey of Japan (GSJ, 2000), Gravity Research Group for Southwestern Japan (The Gravity Research Group in Southwest Japan, 2001), our detailed observation data (Kono et al., 2006) and the satellite altimetry and ship depth soundings (Smith and Sandwell, 1997). The total number of compiled data points is over 13,000 in the research area (Fig. 1). They are spaced approximately one every $2 \mathrm{~km}^{2}$ on the land area. We show the distribution of the gravity stations in Fig. 2. Compiling all these data, we constructed a detailed Bouguer anomaly map of the Noto peninsula (Fig. 3). Many other interesting features of the Bouguer anomalies over the Noto peninsula will be described in another manuscript (Kono et al., in preparation).

All of the compiled data were recalculated using the calculation routine developed by Kanazawa University (Kono and Furuse, 1989). A terrain correction using a 50-m DEM (Honda and Kono, 2005) was then adopted, assuming a density of $2,670 \mathrm{~kg} / \mathrm{m}^{3}$ in the calculation.

\section{Geological Background}

The geology of the Noto peninsula is characterized by large density contrast between Pre-Tertiary basement rocks and Tertiary formations. The basement rocks are composed of Hida Metamorphic rocks and Funatsu Granitic rocks. These basement rocks outcrop widely around the Mt. Hodatsu and Sekidoh mountainous regions (Kaseno, 1993). Some basement outcrops are also found in the source re- 


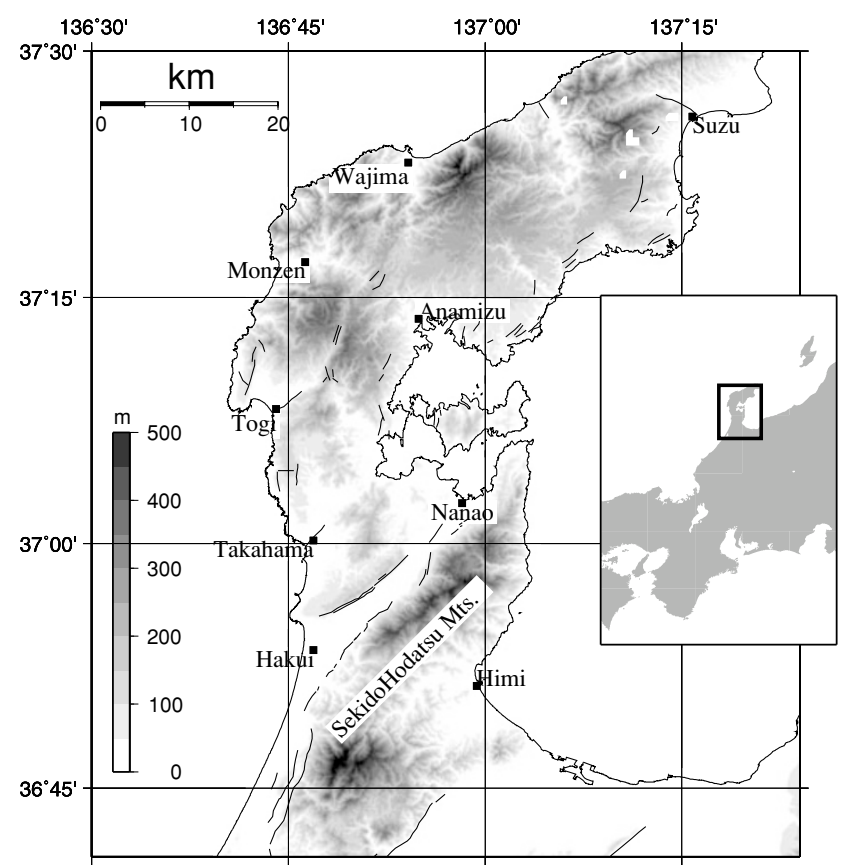

Fig. 1. Topography of the Noto Peninsula. Solid squares indicate the location of major towns, the names of which are described beside. Active faults (Active Fault Research Group, 1991) are indicated with black lines.

gion of the Noto Hanto Earthquake. Generally, the southern part of the Noto peninsula is characterized by outcropping basement rocks, while the middle and the northern parts are covered with Neogene formations. These are mainly composed of hyaloclastic rocks, andesite lava, sandstone and conglomerate. The geologic structure in and around the source region is very complicated, but no large dislocations have been reported. Quaternary sediments are distributed around Togi, Anamizu, Wajima and Takahama.

\section{Gravity Anomalies}

As shown in Fig. 3, the northern and the middle parts of the Noto peninsula show relatively high-gravity anomalies, while the southernmost part shows relatively low anomalies. It is obvious that there is a trend in gravity anomaly over the Noto peninsula. This long wavelength component in the gravity anomaly is attributed to deep structures, such as the subducting plate and undulations of the Moho and/or Conrad discontinuities. For the purpose of focusing on and discussing the shallow structure, we should eliminate this long wavelength component. As it may be difficult to describe the gravity trend as a simple linear plane, we used the "grdtrend" command on Generic Mapping Tools (Wessel and Smith, 1998) to describe the regional trend as a cubic surface. We then subtracted the trend from the observed gravity anomaly (Fig. 4). It is still ambiguous whether the calculated trend correctly simulates the gravity effect from the deep structures. However, it is obvious from Fig. 4 that the major trend shown in Fig. 3 has been removed and that local Bouguer anomalies, such as positive anomalies around the Sekidoh Mountains and northern Togi and negative anomalies around southern Takahama are now emphasized. The positive anomalies show a good correspondence

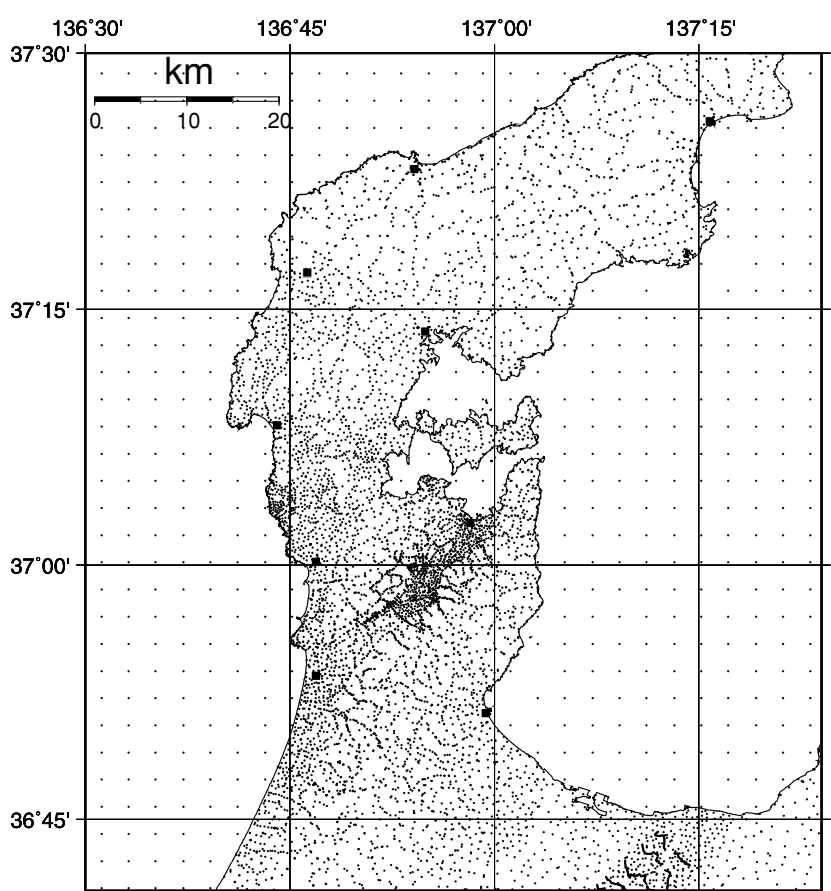

Fig. 2. Distribution of the gravity stations. Black solid circles indicate the locations of all the gravity data compiled in this work. Solid squares indicate the locations of major towns.

with the distribution of outcropping basement rocks.

Figure 4 also shows a comparison between aftershock distributions provided by Japan Meteorological Agency (2007/03/25, 0:00-24:00) and the gravity anomalies. Between Monzen and Wajima, we recognize a NE-SW trending linear distribution of the sharp gradient of the gravity anomaly, along the shallow aftershock distribution. The gravity anomaly is relatively low in the northwestern side and relatively high in the southeastern side. This linear gravity anomaly seems to extend along the northern shore northeast of Wajima. In the sea area, however, the distribution of the data is not dense enough to discuss in detail. The extension to the western sea area is also uncertain for the same reason.

\section{Discussion}

Since one of the largest geologic characteristics of the Noto peninsula is the large density contrast between basement rocks and Tertiary formations, we are able to approximately use the Bouguer anomaly map as an indication of relative basement depth. Fig. 5 shows the geologic block structures over the northern Noto Peninsula (after Ohta et al., 1976) and the Bouguer anomalies. The classification of the block boundaries is based on the height discontinuities of former shorelines of marine terraces. According to the analyses, the northern Noto peninsula is divided into four major bocks: Kuwatsuka (KT), Saruyama (SY), Hachibuse (HB), Houryu (HR). The SY block was reported to show no clear sign of uplift along the coastline between Monzen and Wajima, the other blocks show relatively active uplift. The southern end of the KT block coincides with the northern end of the low anomalies in Takahama. The boundary between HB and the HR is obscure. The linear gravity gra- 


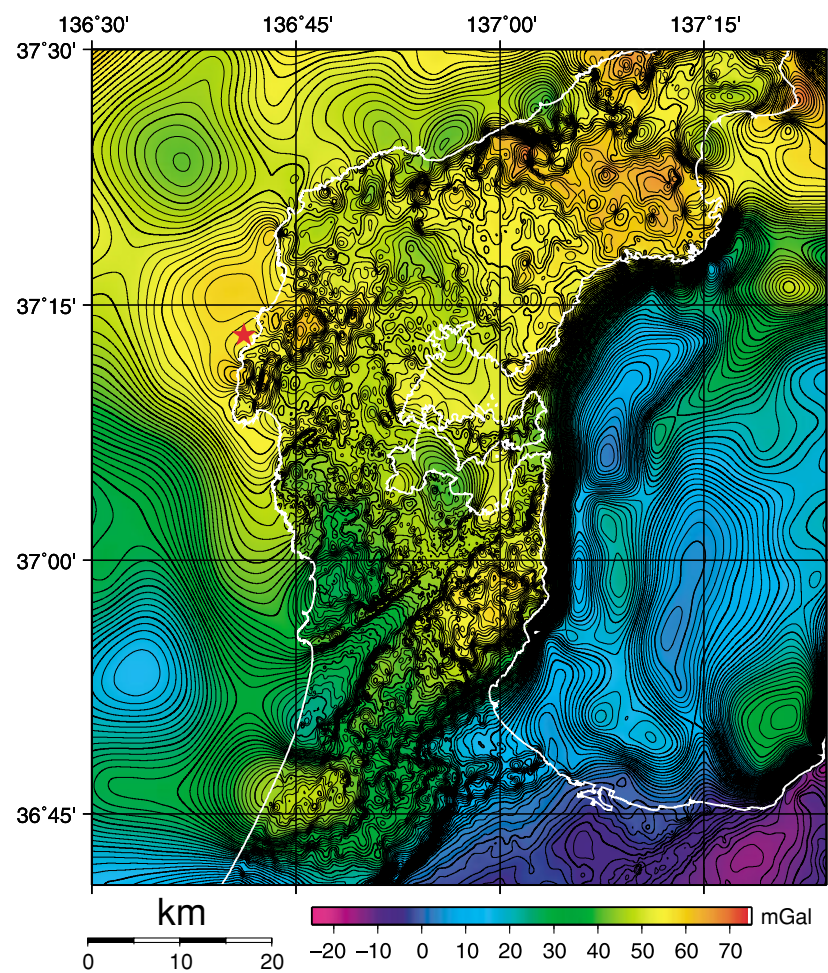

Fig. 3. Bouguer Anomaly map of the Noto Peninsula (Kono et al., in preparation). All data shown in Fig. 2 are compiled. Assumed density is $2,670 \mathrm{~kg} / \mathrm{m}^{3}$. Contour interval is $1 \mathrm{mGal}$. Red solid star indicates the epicenter of the mainshock.

dient distribution mentioned in the previous section is recognized in the SY block. The aftershock area spreads over two of these four blocks, the KT and the SY blocks. In the gravity anomaly distribution, the KT and the SY blocks are clearly recognized by relatively high and low anomalies, respectively. As noted above, this means that the basement depth of the KT block is shallower than that of the SY block. The gap of the former shoreline $(0.12 \mathrm{Ma})$ is at least $50 \mathrm{~m}$ between the SY and the neighboring two blocks, and the difference in the uplift rate is at least $0.42 \mathrm{~m} / 1 \mathrm{ky}$ (Ohta et al., 1976). It can be said that the uplift movement of the KT block, at least for these 120,000 years, has been relatively active compared to that of the SY block. This is consistent with the fact that the Bouguer anomalies of the SY block are lower than those of the KT block. Thus, we assume that the uplift movement of the KT block has been relatively active compared to that of the SY block.

The region of large crustal movement shown in SAR interferometric images (JAXA, 2007; GSI, 2007; Fukushima et al., 2007) corresponds well to the KT block. Additionally, the slip distributions inferred from SAR interferometry indicates a large slip beneath the western sea area (GSI, 2007). AIST (2007) and Hiramatsu et al. (2007) surveyed the uplift and the subsidence along the coastline based on the distribution of midlittoral and infralittoral organisms. They constructed fault models that ruptured only the KT block and found a good match to the observed uplift well. Slip distributions estimated from strong motion data also indicate a large slip area near the mainshock (e.g. Horikawa, 2007) and little slip in the shallow part of the SY block.

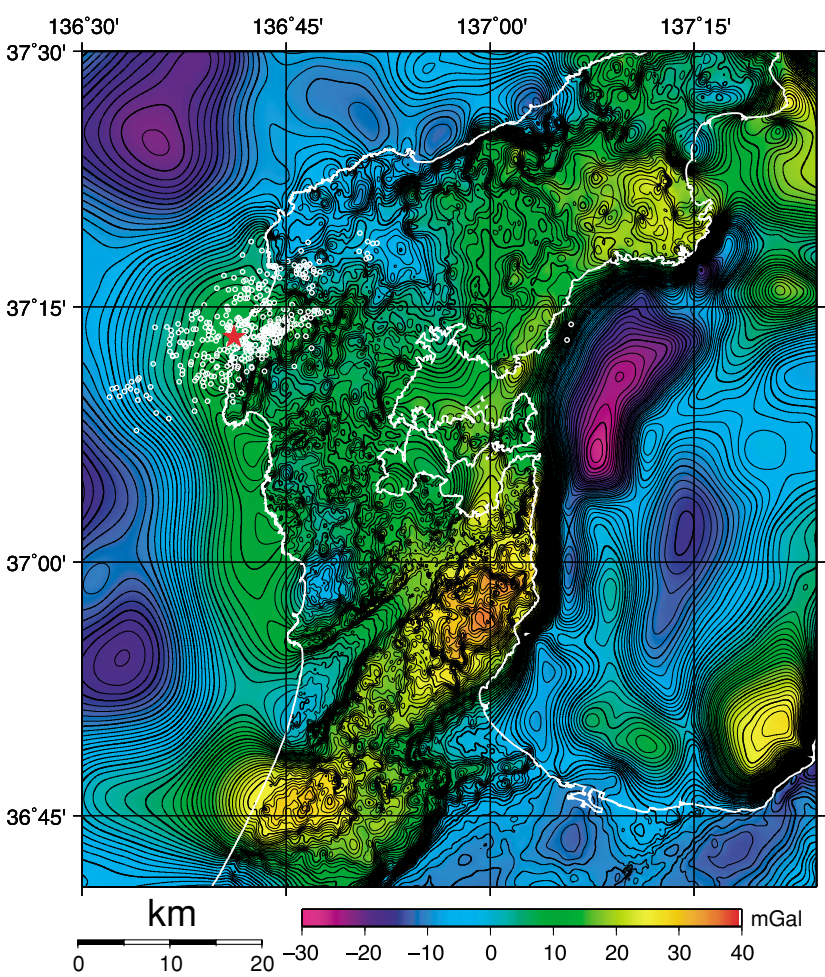

Fig. 4. Filtered Bouguer anomaly map of the Noto peninsula (Kono et al., in preparation). Regional trend of the Bouguer Anomaly was subtracted from the observed anomaly shown in Fig. 3. Assumed density is $2,670 \mathrm{~kg} / \mathrm{m}^{3}$. Contour interval is $1 \mathrm{mGal}$. White open circles indicate aftershocks provided by Japan Meteorological Agency (2007/03/25, 0:00-24:00). Red solid star indicates the epicenter of the mainshock.

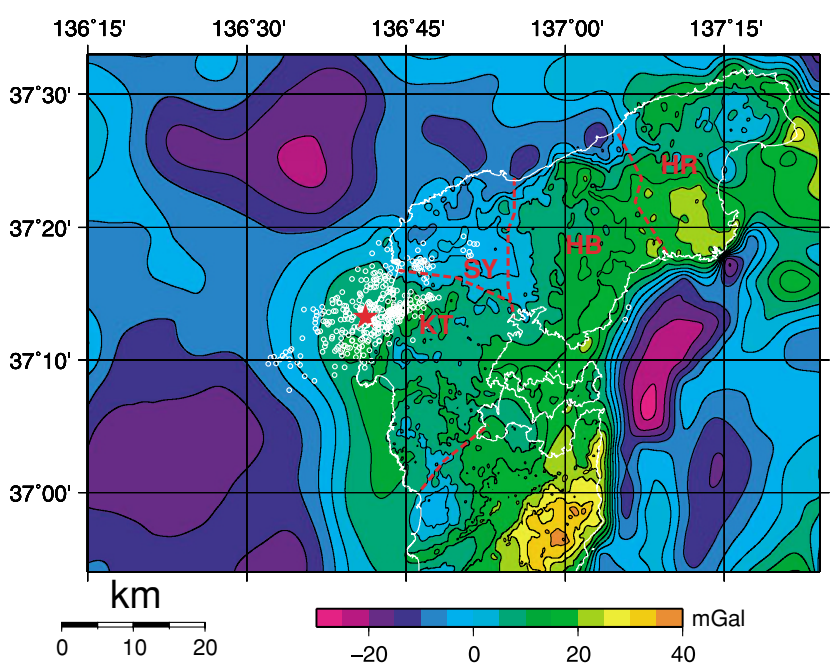

Fig. 5. Filtered Bouguer Anomaly map over the northern Noto peninsula (Kono et al., in preparation) and the block structure of the northern Noto peninsula. Red solid star indicates the epicenter of the mainshock. White open circles indicate aftershocks provided by Japan Meteorological Agency (2007/03/25, 0:00-24:00). Red dashed lines indicate geologic block boundaries proposed by Ohta et al. (1976). Geologic blocks indicated by initials are as follows. KT: Kuwatsuka, SY: Saruyama, HB: Hachibuse and HR: Houryu blocks.

These observations and analyses support the conclusion that the mainshock ruptured only the KT block and that the major crustal uplift occurred in the KT block as well. In other words, the block structures presumably limited the source 

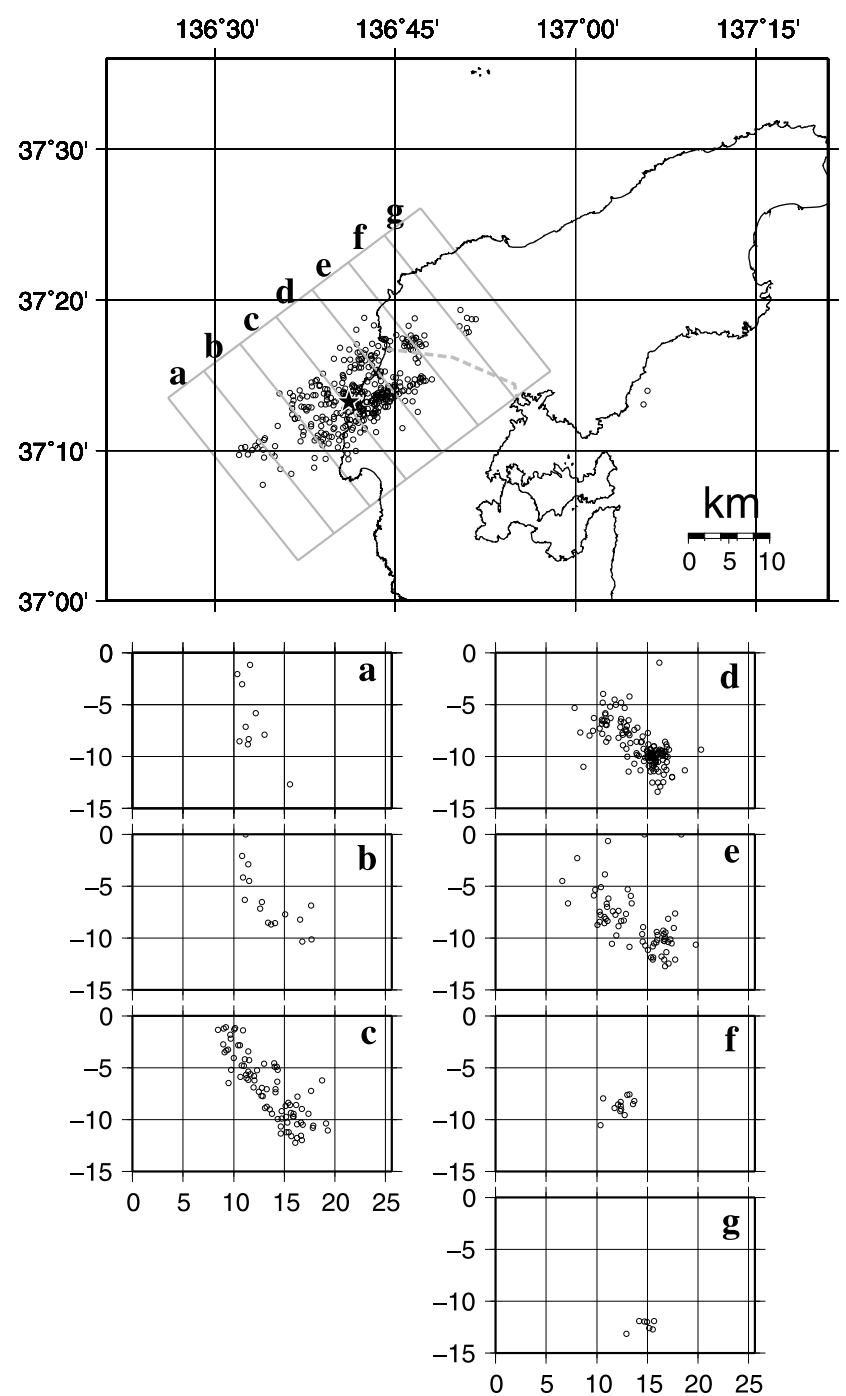

Fig. 6. Aftershocks provided by Japan Meteorological Agency (2007/03/25, 0:00-24:00) and their profiles approximately perpendicular to the strike of the source fault. Side views $(a-g)$ correspond to the profiles of the bounded boxes in the map view. Black solid star with white rim in the map view indicates the epicenter of the mainshock. Gray dashed line in the map indicates the boundary between the KT and the SY block.

size of the Noto Hanto earthquake.

Figure 6 shows aftershock distributions provided by Japan Meteorological Agency, and its vertical crosssections projected approximately perpendicular to the earthquake fault. In plan view, a gap of the aftershock is recognized in the KT block along the KT-SY boundary. In the cross-sectional views, linear distributions are shown in the KT block side. On the other hand, the SY block side does not show linear distribution. At any rate, the aftershock distribution seems to change its pattern near the KT-SY block boundary. This suggests again that the block structure affects the distribution of the aftershocks. This characteristic is also shown in the more accurate aftershock distribution obtaind by "Group for the aftershock observations of the 2007 Noto Hanto Earthquake" (Sakai et al., 2007).

As mentioned above, the Bouguer anomalies reflect the density heterogeneity of the shallow crust, probably as a result of cumulative crustal deformation. Gravity anoma- lies support the block boundaries over the northern Noto peninsula which were proposed based on geological and geographical observations. As mentioned previously, geodetic and seismological analyses also suggested that the rupture had occurred within the KT block. Combining the results of these studies and those of the geological and geomorphological studies cited above, we propose that the rupture size of the 2007 Noto Hanto Earthquake was constrained by the block structure of the northern Noto Peninsula. We believe that detailed investigations of gravity anomaly and geologic structure, as shown in this paper, provide useful information on the size of a typical earthquake in a region.

\section{Summary}

We have constructed a detailed Bouguer anomaly map by compiling all available data. The Bouguer anomaly distribution is closely related to the geologic block structures in the northern Noto peninsula. By relating this to other data, it is probable that the rupture of the mainshock was constrained by the old block structure in the northern Noto peninsula (Ohta et al., 1976).

Acknowledgments. We thank Dr. Hiroaki Takahashi and Mr. Masayoshi Ichiyanagi of the Institute of Seismology and Volcanology, Hokkaido University, for the helpful discussions. Prof. Tony Hurst who gave us many helpful suggestions. He also helped us to improve our English manuscript. Comments from two reviewers also improved our manuscript. We are also grateful to those gave us suggestions and encouragement during the Japan Geoscience Union joint meeting at Makuhari. We used hypocenter data provided by Japan Meteorological Agency. We used Generic Mapping Tools (Wessel and Smith, 1998) for producing all figures.

\section{References}

Active Fault Research Group, Active Faults in Japan: sheet map and inventories (Revised ed.), 437 pp., University of Tokyo Press, Tokyo, 1991 (in Japanese).

Advanced Industrial Science and Technology, http://unit.aist.go.jp/ actfault/katsudo/jishin/notohanto/report/070403.html, 2007.

Earthquake Research Institute, http://www.eri.u-tokyo.ac.jp/topics/ noto20070325/20070325satow2.html, 2007.

Fukushima, Y., T. Ozawa, and M. Hashimoto, Crustal deformation analysis using SAR interferometry on the 2007 Noto Hanto earthquake, Abstract for Japan Geoscience Union Joint Meet., Z255-P019, 2007.

Geographycal Survey Institute of Japan, http://vldb.gsi.go.jp/sokuchi/ gravity/grv_search/gravity.pl, 2002.

Geographycal Survey Institute of Japan, http://gsi.go.jp/WNEW/PRESSRELEASE/2007/0412html, 2007.

Geological Survey of Japan, Gravity CD-ROM of Japan, Digital Geoscience Map P-2, edited by Geological Survey of Japan, 2000.

Hiramatsu, Y., K. Moriya, T. Kamiya, and M. Kato, Fault model of the 2007 Noto Hanto earthquake estimated from coseismic deformation obtained by the distribution of midlittoral and infralittoral organisms and GPS, Earth Planets Space, 2007 (submitted).

Honda, R. and Y. Kono, Synthesized Land and Sea 50 M Digital Elevation Model and Gravimetric Terrain Correction in and around the Japanese Islands, J. Geod. Soc. Japan, 51, 33-44, 2005 (in Japanese with English abstract).

Horikawa, H., Source process of the 2007 Noto-Hanto earthquake (M6.9), Abstract for Japan Geoscience Union Joint Meet., Z255-P008, 2007.

Hoshiba, M., Outline of the Noto Hanto Earthquake in 2007, Abstract for Japan Geoscience Union Joint Meet., Z255-P001, 2007.

Japan Aerospace Exploration Agency, http://www.jaxa.jp/press/2007/04/ 20070412_daichi_j.html, 2007.

Kaseno, Y., Geology of Ishikawa-ken, Japan (with Geological Maps), $321 \mathrm{pp}$, Ishikawa prefecture and Hokuriku Geology Institute, Ishikawa, 1993 (in Japanese).

Katagawa, H., M. Hamada, S. Yoshida, H. Kadosawa, A. Mitsuhashi, Y. Kono, and Y. Kinugasa, Geological Development of the West Sea Area 
of the Noto Peninsula District in the Neogene Tertiary to Quaternary, Central Japan, J. Geogr., 114, 791-810, 2005 (in Japanese with English abstract).

Kono, Y. and N. Furuse, 1 in 1 Million Scale Gravity anomalies over the Japanese Islands, 79 pp., University of Tokyo Press, Tokyo, 1989 (in Japanese).

Kono, Y., R. Honda, and M. Hamada, Gravity anomalies around middle part of the Noto peninsula, Abstract for Seism. Soc. Japan 2006 fall meeting, D58, 2006.

Kono, Y., R. Honda, M. Hamada, and H. Katagawa, Gravity anomalies and geological structure of central part of the Noto Peninsula, Zisin, (in preparation).

Ohta, Y., T. Matsuda, and K. Hirakawa, Active faults in Noto Peninsula, Central Japan, The Quaternary Research, 15, 109-128, 1976 (in Japanese with English abstract).

Sakai, S., T. Iidaka, and Group for the aftershock observations of the
2007 Noto Hanto Earthquake, Aftershock observation of the Noto Hanto Earthquake in 2007 by temporary seismic observations, Abstract for Japan Geoscience Union Joint Meet., Z255-P050, 2007.

Smith, W. H. F. and D. T. Sandwell, Global Seafloor Topography from Satellite Altimetry and Ship Depth Soundings, Science, 277, 19571962, 1997.

The Gravity Research Group in Southwest Japan, Gravity Measuremnts and Database in Southwest Japan, Gravity Database of Southwest Japan (CD-ROM), Bull. Nagoya University Museum, Special Rep., No. 9, 2001.

Wessel, P. and W. H. F. Smith, New, improved version of the Generic Mapping Tools released, EOS Trans. AGU, 79, 579, 1998.

R. Honda (e-mail: honda05@mail.sci.hokudai.ac.jp), Y. Hiramatsu, Y. Kono, and H. Katagawa 